\title{
La Industria 4.0 en perspectiva latinoamericana: limitaciones, oportunidades y desafíos para su desarrollo
}

The development of 4.0 industry from a Latin American perspective: shortcomings, opportunities, challenges

\section{Patricio Julián Feldman \\ Doctor en Ciencias Sociales (UBA). Becario posdoctoral del CONICET. Miembro del Programa de \\ Investigaciones sobre la Sociedad de la Información, Instituto de Investigadores Gino Germani (Facultad de Ciencias Sociales, Universidad de Buenos Aires) patofeldman@gmail.com}

\section{Ulises Girolimo}

Doctor en Ciencias Sociales (UBA). Becario posdoctoral del CONICET. Miembro del Programa de Investigaciones sobre la Sociedad de la Información, Instituto de Investigadores Gino Germani (Facultad de Ciencias Sociales, Universidad de Buenos Aires)

ugirolimo@gmail.com

Fecha de recepción:

30.7.20

Fecha de aceptación:

18.11.20

\section{Resumen}

El artículo analiza las políticas de promoción de la industria 4.0 (I4.0) en América Latina, tomando los casos de México, Argentina y Brasil, en un contexto de cambio tecnológico acelerado por la irrupción de las tecnologías 4.0. Además, se abordan las estrategias de los países líderes para conducir el proceso de digitalización y automatización de los procesos productivos, y la necesidad de afrontar estos desafios por parte de las economías periféricas para no profundizar las brechas existentes respecto a los países centrales. Una interrogante recorre transversalmente el texto: ¿Cuáles son los obstáculos y desafíos que deben afrontar México, Argentina y Brasil para delinear un modelo latinoamericano de desarrollo de la I4.0?

Palabras clave: industria 4.0 - cambio tecnológico - políticas públicas - desarrollo socio-Económico - América Latina. 


\begin{abstract}
The article discusses the policies for the promotion of the Industry 4.0 in Latin America. It focuses on Mexico, Argentina and Brazil, in a context of an accelerated technological change by the irruption of 4.0 technologies. Furthermore, it focuses on the leading countries strategies for digitalization and automatization of production processes, as well the relevance for peripheral economies to face these challenges in order to avoid deepening the existing gaps between them and the central countries. A question that crosses the text is: Which barriers and challenges must face Mexico, Argentina and Brazil to develop a Latin American model for I4.0 development?
\end{abstract}

Key words: industry 4. - technological change - public policies - socio-economic development - Latin America.

\title{
1. Introducción
}

El presente trabajo se inscribe dentro del proyecto de investigación PICT 2018: “Tecnologías 4.0 para la Industria Argentina - Análisis y herramientas de I\&D+i para la formulación de políticas y el desarrollo de la Industria 4.0", que se propone construir el estado del arte de la investigación asociada a la temática en Argentina, en el periodo 2013-2020, y su vinculación con las Pequeñas y Medianas Empresas (PyMES) industriales; y desarrollar instrumentos que permitan la formulación y optimización de las políticas públicas dirigidas tanto a la investigación científico-tecnológica en tecnologías 4.0, como a su aplicación en los sector productivos.

Este artículo en particular se propone analizar las políticas de promoción de la Industria 4.0 (I4.0) en América Latina en el contexto de un debate global respecto al carácter rupturista del cambio tecnológico vigente, el rol de los países líderes y sus estrategias para conducir el proceso de digitalización y automatización de los procesos productivos. Además, se plantea reflexionar en torno a la necesidad estratégica de abordar estos desafios por parte de las economías periféricas a los fines de no profundizar las brechas existentes respecto a los países centrales en el campo del desarrollo tecnológico y productivo.

Las tecnologías 4.0 y su impacto en el desarrollo socio-económico han llevado a diversos autores a considerar que se está ante las puertas de un nuevo paradigma tecnoeconómico. 
En este artículo dicha afirmación es matizada al sostener que la frontera tecnológica del paradigma basado en las Tecnologías de Información y Comunicación (TIC) no ha sido superada. Por el contrario, existiría una profundización del mismo como consecuencia de la convergencia y evolución de un conjunto de tecnologías preexistentes.

Diferentes términos fueron acuñados con la finalidad de captar esta especificidad: Industria 4.0 es quizás el más expandido en la agenda pública a punto tal que organismos internacionales, agencias gubernamentales, medios de comunicación, asociaciones empresarias, sindicatos e investigadores científicos, comenzaron a incorporarlo a sus campos de intervención.

El trabajo considera que este debate es importante para América Latina en tanto permite formular una serie de interrogantes: ¿Se abre una ventana de oportunidad para delinear estrategias exitosas que conduzcan al desarrollo económico y al cambio tecnológico, o más bien se profundiza la dependencia estructural y tecnológica con respecto a las economías centrales? ¿En qué medida y bajo qué condiciones es posible acortar brechas con dichos países en la actual etapa capitalista? ¿Cuáles son los obstáculos a superar y de qué modo están afrontando los desafios que impone la etapa actual países como México, Brasil y Argentina?

En la segunda sección se analiza el surgimiento, las características y tendencias exhibidas por la I4.0 en la última década; así como las especificidades de los sistemas tecnológicos aglutinados bajo dicho término, y los puntos de contacto y separación con el paradigma TIC. En la tercera se analizan las iniciativas internacionales desplegadas en la actualidad por los países líderes en el desarrollo e incorporación de tecnologías 4.0 para la producción, como Alemania, Estados Unidos y China. De su análisis se desprenden ciertos elementos comunes: a) una fuerte participación estatal en la promoción de la I4.0 y la definición de marcos regulatorios para la actividad científico-tecnológica e industrial; b) una marcada interacción entre actores sociales diversos, como grandes empresas, PyMES, universidades, centros de investigación y Estado; y c) la implementación de mecanismos de cooperación internacional que incluyen la formación de consorcios entre empresas de alta tecnología, el sector industrial y las instituciones del sistema científico-tecnológico.

Cada uno de estos países delineó un modelo de desarrollo particular de la I4.0 en función de sus objetivos estratégicos: en el caso alemán se observa la búsqueda por sostener una posición hegemónica en tanto país industrial innovador (Schteingart et al 2019), en el estadounidense el intento de recuperar una posición de liderazgo en la producción manufacturera; en el chino la búsqueda por alcanzar una posición hegemónica en la economía internacional por medio de una transformación en su estructura productiva y el perfil de sus exportaciones.

En la cuarta sección se indaga sobre la experiencia, todavía incipiente, de tres países latinoamericanos para desarrollar la I4.0: México, Argentina y Brasil. La selección de casos responde a que son las economías más industrializadas de la región, tienen mayores 
capacidades tecnológicas que el resto de los países latinoamericanos y han iniciado un recorrido en el diseño de políticas explícitas para su desarrollo. El análisis no se encuentra escindido de una serie de condicionantes estructurales y tecnológicas, como la dependencia y atraso tecnológico e institucional frente a las economías centrales, la marcada debilidad de los sistemas nacionales de innovación, el déficit en la infraestructura tecnológica y la conectividad, la escasez de capital humano calificado, entre otros.

En esa misma sección se analizan los instrumentos desarrollados de forma directa para estimular la I4.0 en los tres países, que revela un mayor grado de maduración de la política mexicana frente a las incipientes iniciativas implementadas por Argentina y Brasil. En concordancia con la experiencia internacional desarrollada por los países líderes, México orienta su estrategia hacia la conformación de redes multiactorales por medio del estímulo a clústeres tecnológicos especializados en tecnologías 4.0 y prioriza la formación de capital humano especializado. Por su parte, la política argentina evidencia un carácter incipiente que se ve reforzado por el cambio de gobierno en diciembre de 2019 y la emergencia de la pandemia del coronavirus, que constituyen un contexto adverso para el diseño de políticas estratégicas. En Brasil se observa una multiplicidad de instrumentos con escasa coordinación y altamente superpuestos.

Finalmente, se presentan las reflexiones finales y los principales desafios que enfrentan los países latinoamericanos para superar los obstáculos señalados. Dado que el estadio de las tecnologías 4.0 se encuentra todavía lejos de su maduración, los cambios de gobierno entre 2018 y 2019, y la explosión de la pandemia que está azotando al mundo, es posible considerar que el escenario sobre el desarrollo de la I4.0 en la región se encuentra abierto e indeterminado.

\section{Industria 4.0: definiciones y tendencias globales}

El término Industria 4.0 emergió a comienzos de la década de 2010 en Alemania. Fue acuñado por un grupo de especialistas convocados por el gobierno para elaborar un programa de mejora de la productividad en la industria manufacturera (Albrieu et al 2019; Basco et al 2018), cuyo objetivo era posicionar a la industria alemana como referente internacional en la oferta y demanda de tecnologías digitales aplicadas a la producción (Schroeder 2016). Posteriormente, en el marco del $46^{\circ}$ Foro Económico Mundial, Schwab (2016) acuñó el término Cuarta Revolución Industrial (4RI) para referirse al surgimiento de una nueva revolución tecnológica que tiene como elemento distintivo la transición hacia los nuevos sistemas ciberfisicos.

Ambos términos irrumpieron con fuerza en la agenda pública. Organismos internacionales, agencias gubernamentales, medios de comunicación, asociaciones empresarias, sindicatos e investigadores científicos, comenzaron a incorporarlos en sus campos de intervención. Este fenómeno está asociado al desarrollo de un conjunto de tecnologías que estarían contribuyendo a producir cambios profundos a nivel económico, social y productivo. En el Cuadro $\mathrm{N}^{\circ}$ 1 se exponen las principales características de las tecnologías que componen el universo 4.0. 
Cuadro $\mathbf{N}^{\circ}$ 1: Principales características de las tecnologías 4.0 aplicadas a la industria

\begin{tabular}{|c|c|c|c|c|}
\hline Tecnología & Características & Dispositivos/Componentes & Empresas líderes & Año de surgimiento \\
\hline $\begin{array}{l}\text { Internet de las } \\
\text { Cosas (IoT) }\end{array}$ & $\begin{array}{l}\text { Comunicación multidireccional } \\
\text { entre máquinas, objetos, y personas, } \\
\text { a través del uso de sensores y } \\
\text { conexión a Internet. Permite recoger } \\
\text { información del entorno para } \\
\text { mejorar la toma de decisiones a nivel } \\
\text { productivo y comercial. }\end{array}$ & $\begin{array}{l}\text { Sensores, redes, codificadores y } \\
\text { decodificadores, y software }\end{array}$ & $\begin{array}{l}\text { CiscoIBM / Intel } \\
\text { G. E. / Google } \\
\text { Microsoft } \\
\text { Salesforce } \\
\text { Oracle / Qualcomm } \\
\text { Amazon }\end{array}$ & 2008-2009 \\
\hline $\begin{array}{l}\text { Inteligencia } \\
\text { Artificial } \\
(I A)\end{array}$ & $\begin{array}{l}\text { Desarrollo de algoritmos que permiten } \\
\text { potenciar el procesamiento de } \\
\text { información a través del aprendizaje } \\
\text { automático. Estos adquieren capacidades } \\
\text { cognitivas similares a las redes neuronales } \\
\text { humanas: visión, lenguaje, comprensión, } \\
\text { decisión en base a datos, etc. }\end{array}$ & $\begin{array}{l}\text { Software y algoritmos } \\
\text { matemáticos }\end{array}$ & $\begin{array}{l}\text { Amazon } \\
\text { Google } \\
\text { Microsoft } \\
\text { Huawei } \\
\text { Apple }\end{array}$ & 1997 \\
\hline $\begin{array}{l}\text { Computación } \\
\text { en la Nube }\end{array}$ & $\begin{array}{l}\text { Almacenar grandes volúmenes de } \\
\text { datos generados durante el proceso } \\
\text { productivo de forma remota y reducir } \\
\text { costos evitando adquirir servidores, } \\
\text { licencias y personal especializado para } \\
\text { el mantenimiento de los mismos. }\end{array}$ & Servidores & $\begin{array}{l}\text { Microsoft } \\
\text { Amazon Google } \\
\text { Storage } \\
\text { IBM } \\
\text { Salesforce } \\
\text { SAP }\end{array}$ & 1999 \\
\hline Big Data & $\begin{array}{l}\text { Análisis de grandes volúmenes de } \\
\text { datos. Reduce ineficiencias del proceso } \\
\text { productivo, anticipa fallas en equipos y } \\
\text { brinda mejores respuestas a situaciones } \\
\text { emergentes e imprevistas. Permite } \\
\text { tomar decisiones en tiempo real para } \\
\text { mejorar la eficiencia productiva y } \\
\text { definir modelos de negocios basados en } \\
\text { comportamientos de clientes. }\end{array}$ & Base de datos y software & $\begin{array}{l}\text { IBM } \\
\text { Microsoft } \\
\text { SAP } \\
\text { Amazon } \\
\text { Google } \\
\text { HP }\end{array}$ & 2004 \\
\hline $\begin{array}{l}\text { Sistemas de } \\
\text { integración }\end{array}$ & $\begin{array}{l}\text { Integran tecnologías operacionales con } \\
\text { tecnologías informacionales. Por medio } \\
\text { de plataformas digitales, hacen posible } \\
\text { la conexión de la unidad productiva } \\
\text { con otros actores de la cadena de valor. }\end{array}$ & $\begin{array}{l}\text { Sistemas de control basados } \\
\text { en red, software y sistemas } \\
\text { operativos }\end{array}$ & $\begin{array}{l}\text { Siemens } \\
\text { Deloitte } \\
\text { IBM }\end{array}$ & 2014 \\
\hline Impresión $3 D$ & $\begin{array}{l}\text { Posibilita la fabricación de piezas a } \\
\text { partir de la superposición de capas de } \\
\text { distintos materiales sobre la base de } \\
\text { un diseño moldeado de forma virtual. } \\
\text { De esta forma, es posible producir } \\
\text { formas geométricas personalizadas en } \\
\text { lotes pequeños o series cortas. }\end{array}$ & Impresoras y software & $\begin{array}{l}\text { Voxeljet } \\
\text { Stratasys } \\
\text { 3dsystems } \\
\text { Solidscape } \\
\text { LC Printing } \\
\text { Machine Factory } \\
\text { Limited }\end{array}$ & 2006 \\
\hline $\begin{array}{l}\text { Realidad } \\
\text { virtual } y \\
\text { realidad } \\
\text { aumentada }\end{array}$ & $\begin{array}{l}\text { Representación virtual del } \\
\text { funcionamiento conjunto de máquinas, } \\
\text { procesos y personas en tiempo real, } \\
\text { a los fines de ahorrar costos en los } \\
\text { procesos de aprendizaje, desplazando } \\
\text { este ámbito al entorno virtual. Facilita } \\
\text { la complementariedad del entorno real } \\
\text { con objetos digitales, mejorando los } \\
\text { sistemas de simulación y modelado. }\end{array}$ & $\begin{array}{l}\text { Headsets y dispositivos } \\
\text { específicos para capturar } \\
\text { objetos tridimensionales }\end{array}$ & $\begin{array}{l}\text { Apple } \\
\text { Google } \\
\text { Microsoft } \\
\text { 3Dconnexion } \\
\text { Facebook } \\
\text { HTC } \\
\text { Samsung }\end{array}$ & $2000-2003$ \\
\hline $\begin{array}{l}\text { Robots } \\
\text { autónomos }\end{array}$ & $\begin{array}{l}\text { Máquinas inteligentes que } \\
\text { automatizan tareas previamente } \\
\text { desarrolladas por humanos. En la } \\
\text { 4RI se busca incrementar la robótica } \\
\text { colaborativa, es decir, aquélla capaz } \\
\text { de interactuar con humanos en un } \\
\text { espacio de trabajo compartido. }\end{array}$ & $\begin{array}{l}\text { Robots, software y algoritmos } \\
\text { matemáticos }\end{array}$ & $\begin{array}{l}\text { Epson } \\
\text { Google } \\
\text { Yaskawa } \\
\text { Kuka }\end{array}$ & 1971 \\
\hline
\end{tabular}

Fuente: Elaboración propia en base a Basco et al (2018), Brixner et al (2019) y Baum (2015) 
La profundidad de las transformaciones producidas ha llevado a que diversos autores consideren que se está ante las puertas de lo que Pérez (2010) denominaría nuevo paradigma tecnoeconómico, cuya principal novedad es la informatización y la transformación digital de la producción por medio de sistemas ciberfisicos (Chung y Kim 2016; Schwab 2016 Kagermann et al 2013; Lasi et al. 2014a; Klingenberg y Do Vale Antunes 2017).

Existe cierto consenso en la literatura respecto a que la 4RI introduce al menos dos cambios significativos respecto a la Tercera Revolución Industrial (3RI) estructurada en base a las TIC. En primer lugar, la aceleración de la automatización de la producción y la conformación de sistemas ciberfísicos inteligentes transforman los límites entre lo fisico, lo biológico y lo digital, y posibilitan la interconexión e interoperabilidad entre artefactos, reduciendo la necesidad de intermediación humana (Basco et al 2018). También se producen transformaciones en la organización de la producción en la cual la gobernanza del proceso productivo recae cada vez más en los algoritmos, lo que habilita la configuración de un modelo de empresa algoritmo (Zukerfeld 2020). ${ }^{1}$

En segundo lugar, la construcción de una nueva infraestructura y soporte tecnológico permite sostener el funcionamiento de los sistemas ciberfisicos de producción. La llamada 5G posibilitaría, en los términos de Brynjolfsson y McAfee (2016), la conformación de una red digital común, o en los de Rifkin (2014), una neurored mundial, que conecta personas y artefactos, y permitiría almacenar un volumen extraordinario de datos en la nube.

Por otra parte, diversos autores señalan que el conjunto de tecnologías 4.0 y sus impactos en los procesos productivos, no estarían generando una ruptura sino un avance en la trayectoria evolutiva del paradigma tecnoeconómico vigente desde la década del setenta (Baum 2015; Brixner et al 2019; Casalet 2018; Schroeder 2016).

Al menos dos argumentos permiten sostener esta posición. En primer lugar, las tecnologías 4.0 se encontrarían orientadas a la convergencia de dispositivos y desarrollos científicos preexistentes, como se mostró en el Cuadro $\mathrm{N}^{\circ} 1$. La fuerte integración entre diversas tecnologías que debilitan los límites entre lo físico, lo digital y lo biológico es posible gracias a la conexión de objetos a Internet, la aparición de plataformas para intermediar entre usuarios, el perfeccionamiento de algoritmos que permiten la automatización de procesos, y la clasificación, procesamiento y análisis de grandes volúmenes de datos (Basco et al 2018; Brixner et al 2019; Galliano 2020).

En segundo lugar, no se revelaría una modificación sustancial del factor clave de producción (Pérez 2010) -comprendido como el insumo o conjunto de insumos capaces de ejercer una influencia determinante en el comportamiento de la estructura de costos relativos dominante en la revolución TIC. Si el bit constituye el factor clave del paradigma TIC, por el momento no podría afirmarse que esté siendo reemplazado -como podría ser a futuro por medio del qubit, unidad de referencia de la computación cuántica-. 
¿Por qué es importante el debate respecto a la configuración de un nuevo paradigma o la profundización del actual para los países de América Latina? ¿Se abre una ventana de oportunidad para la región de ser protagonista en caso de estar ante las puertas de una nueva revolución tecnológica? ¿ O, por el contrario, se multiplican las limitaciones y obstáculos para romper la dependencia tecnológica estructural respecto a las economías centrales?

Estas interrogantes serán abordadas en las secciones siguientes; se espera que las reflexiones en torno a ellas constituyan un aporte al debate actual y futuro sobre las condiciones para impulsar la I4.0 en la región latinoamericana.

\section{Iniciativas internacionales para la promoción de la I4.0: ¿Cómo trabajan los países líderes?}

La I4.0 se desenvuelve en el marco de una fase creciente de concentración oligopólica del mercado asociada a la integración sistémica de las TIC en la producción industrial (Brixner et al 2019). Un grupo reducido de grandes empresas líderes en el desarrollo TIC (Google, Microsoft, IBM, GE, etc.) tejen redes con otro grupo reducido de grandes empresas del sector industrial (Siemens, Bosch, ABB, Philips, Honda, etc.). En este contexto, países innovadores industriales ${ }^{2}$ (Schteingart et al, 2019) como Alemania y Estados Unidos ocupan un rol de preponderancia en el desarrollo de la I4.0, en tanto sus sistemas nacionales de innovación disponen de capacidades tecnológicas de vanguardia, y las empresas pioneras en sistemas de integración y convergencia de tecnologías 4.0 en la industria, tienen su origen allí. Pero además, el factor diferencial radica en que estos países "han implementado decisiones públicas y privadas en el diseño de programas y proyectos para reorientar sectores productivos estratégicos y apropiarse de las oportunidades de esta fase industrial" (Casalet 2018: 5).

A diferencia de Estados Unidos y Alemania, China exporta mayoritariamente manufacturas de medio y alto contenido tecnológico (Schteingart et al, 2019). ${ }^{3}$ En el contexto del alto desarrollo exhibido por el paradigma tecnológico actual, el Estado chino ha desarrollado políticas para transformar la matriz productiva hacia una participación más amplia de la manufactura industrial con alto contenido innovador. La posibilidad de este país de transformarse en un líder del desarrollo de la I4.0 responde a una estrategia con proyección a futuro: la compra de empresas de alta tecnología europeas y estadounidenses con la finalidad de adquirir conocimientos respecto al uso de tecnologías emergentes, el apoyo estatal a clústeres y empresas multinacionales chinas para incrementar su competitividad internacional, el estímulo para la formación de capital humano en el exterior, y el incremento sostenido en la inversión en I+D en áreas de computación e ingeniería, entre otras, son ejemplos de ello (Casalet 2018).

Para ilustrar la relevancia de China en la disputa por liderar el proceso de cambio tecnológico se observa que en 2018 fue el país con mayor solicitud de patentes del mundo: 
de las 3.326.300 solicitudes a nivel mundial, 1.542.002 (46,3\%) se presentaron en China y 597.141 (17,9\%) en Estados Unidos. En ambos casos, se evidencia una especialización en sectores tecnológicos ligados a la tecnologías informáticas (OMPI 2019).

En el Cuadro $N^{\circ} 2$ se presentan las principales características puestas en evidencia en los tres países líderes en el desarrollo de la I4.0. A pesar de sus diferencias, se destacan tres aspectos que constituyen los pilares de estas experiencias. En primer lugar, se identifica una fuerte intervención estatal para orientar recursos, implementar políticas públicas de promoción de la I4.0 y definir un marco regulatorio general para la actividad científicotecnológica e industrial. En segundo lugar, se evidencia una marcada interacción entre actores como grandes empresas, PyMES, universidades, centros de investigación y Estado, con el objetivo de generar redes y un marco estable de cooperación científico-tecnológica en áreas seleccionadas para el desarrollo industrial. Por último, se destaca la implementación de mecanismos de cooperación internacional que incluyen la formación de consorcios entre grandes empresas de alta tecnología, el sector industrial, y las instituciones de ciencia, tecnología e innovación, en sectores vinculados a las tecnologías 4.0. 
Cuadro N²: La promoción de la I4.0 en países líderes

\begin{tabular}{|c|c|c|c|}
\hline Caso / Año & Marco regulatorio / Iniciativas & $\begin{array}{l}\text { Lineamientos de la política } \\
\text { pública en función de los } \\
\text { marcos regulatorios e iniciativas }\end{array}$ & Orientación general \\
\hline $\begin{array}{l}\text { Alemania } \\
2010\end{array}$ & $\begin{array}{l}\text { High Tech Strategy (2006) } \\
\text { Plan de Acción para la Estrategia de } \\
\text { Alta Tecnología } 2020 \text { (2010) } \\
\text { Smart FactoryKL Technology } \\
\text { Platform Industry } 4.0\end{array}$ & $\begin{array}{l}\text { Fábrica público-privada de proveedores } \\
\text { para la aplicación industrial de TIC. } \\
\text { Redes de I+D entre industria y } \\
\text { academia. } \\
\text { Redes abiertas de transferencia } \\
\text { tecnológica. } \\
\text { Creación de modelo uniforme de } \\
\text { referencia para la I4.0. } \\
\text { Instrumentos de cooperación } \\
\text { Internacional. } \\
\text { Creación de una plataforma de I4.0 } \\
\text { entre organizaciones del sector público } \\
\text { y privado, liderada por el Estado. }\end{array}$ & $\begin{array}{l}\text { Integración de sistemas ciberfisicos en } \\
\text { manufactura y logística, utilización de } \\
\text { IoT e incorporación de servicios en } \\
\text { procesos industriales con impacto en } \\
\text { toda la cadena de valor en el ciclo de } \\
\text { vida del producto. } \\
\text { Consolidar a Alemania como líder } \\
\text { de la producción industrial y como } \\
\text { proveedor mundial de soluciones } \\
\text { para la I4.0. }\end{array}$ \\
\hline $\begin{array}{l}\text { EEUU } \\
2014\end{array}$ & $\begin{array}{l}\text { Programa Nacional de Manufactura } \\
\text { Avanzada } \\
\text { Manufacturing USA } \\
\text { American Makes }\end{array}$ & $\begin{array}{l}\text { Red público-privada que aglutina } \\
\text { empresas, instituciones de gobierno e } \\
\text { institutos de investigación activos en } \\
\text { innovación en manufactura. } \\
\text { Manufacturing Extension Partnership } \\
\text { (MEP): capacitación y asistencia técnica } \\
\text { a fábricas inteligentes en los } 50 \text { Estados. } \\
\text { Consorcios de colaboración } \\
\text { entre empresas, agencias estatales, } \\
\text { organizaciones sin fines de lucro e } \\
\text { instituciones académicas. } \\
\text { Aumento de la I+D pública y privada } \\
\text { en áreas estratégicas de la I4.0. }\end{array}$ & $\begin{array}{l}\text { Creación de una estructura } \\
\text { organizativa de apoyo público- } \\
\text { privado para la digitalización } \\
\text { de la industria, el fomento de la } \\
\text { investigación aplicada y el diseño de } \\
\text { nuevas redes institucionales. }\end{array}$ \\
\hline $\begin{array}{l}\text { China } \\
2015\end{array}$ & $\begin{array}{l}\text { Plan General de China } 2025 \\
\text { Made in China } 2025 \\
\text { Nueva Ruta de la Seda Digital }\end{array}$ & $\begin{array}{l}\text { Incremento de la inversión pública y } \\
\text { privada en I+D en áreas estratégicas } \\
\text { de la I4.0. } \\
\text { Patrocinio estatal integral que cubre } \\
\text { casi todas las ramas de la industria } \\
\text { (prioriza la aeroespacial, fabricación de } \\
\text { máquinas para industria y manufactura } \\
\text { de automóviles). } \\
\text { Política de formación de talentos en } \\
\text { el exterior. } \\
\text { Apoyo al desarrollo de clústeres } \\
\text { y empresas multinacionales con } \\
\text { competitividad internacional } \\
\text { (Alibaba, Baidu, Tencent, etc.). } \\
\text { Colaboración con grandes compañías } \\
\text { como ABB, Cisco, IBM, GE. } \\
\text { Instrumentos de cooperación } \\
\text { internacional. }\end{array}$ & $\begin{array}{l}\text { Creación de grupos con actividades } \\
\text { intensivas en conocimiento y } \\
\text { cadenas de valor internacional. } \\
\text { Fortalecer al sector manufacturero } \\
\text { con el objetivo de ser líder en } 2050 \text {, } \\
\text { entre los países industrializados. } \\
\text { Incrementar la productividad entre } \\
\text { un } 25 \% \text { y } 30 \% \text { por medio de la } \\
\text { automatización y digitalización de } \\
\text { la producción. }\end{array}$ \\
\hline
\end{tabular}

Fuente: elaboración propia en base a Artemis Strategic Research Agenda (2016), Digital Transformation Monitor (2017), Plattform Industrie 4.0 (2016), Deloitte (2017), Ezell (2016), Zhang et al (2016), Ma H et al (2018), Casalet (2018), Erbes et al (2019), Castillo et al (2017).

Se observa en ese cuadro que los tres países establecieron marcos regulatorios tanto para la actividad científico-tecnológica como para el sector industrial; y planes nacionales con lineamientos concretos respecto a pasos a seguir y objetivos a cumplir.

Sobre la base de esos lineamientos, es posible identificar tres estrategias para el desarrollo de la I4.0. El modelo alemán busca mantener el estatus de líder innovador industrial a partir de la especialización en la fabricación de sistemas ciberfísicos aplicados a la industria. 
Se puede denominar a esta estrategia como supervivencia de la posición hegemónica, ya que el gobierno buscó desarrollar iniciativas para mantener su liderazgo en la industria manufacturera, en un contexto de fuerte digitalización dominada por grandes plataformas con origen en Estados Unidos (Erbes et al 2019). El modelo estadounidense busca digitalizar el aparato productivo industrial con la finalidad de transformar al país en un líder innovador industrial, luego del proceso de deslocalización de los procesos productivos ocurrido a partir de la década del setenta (Grossman y Rossi-Hansberg 2008). A pesar de ser líder en la producción de servicios tecnológicos, EEUU ha ido perdiendo liderazgo en la producción manufacturera y pretende recuperar esa posición jerárquica en la economía mundial (Castillo et al 2017). Se puede caracterizar a esta estrategia como la búsqueda por retornar a una posición hegemónica en la producción manufacturera. El modelo chino busca transformar al país en un líder mundial perteneciente al grupo de los países innovadores industriales, modificar su matriz productiva y el perfil de sus exportaciones. Se puede denominar a esta estrategia como la búsqueda de una posición hegemónica a partir de los mencionados esfuerzos por liderar el desarrollo de las tecnologías digitales, en un marco de "cierto rezago en materia de capacidades tecnológicas en la manufactura, y una estrategia nacional de catching up tecnológico" (Erbes et al 2019). En todos los casos, el concepto de hegemonía se circunscribe a la disputa por ocupar una posición de jerarquía en las cadenas globales de valor.

Las tres estrategias se enmarcan en una puja entre China y Estados Unidos que no sólo se refiere a una contienda geopolítica que se expresa a través de una guerra comercial, sino que incluye un trasfondo de disputa por el dominio tecnológico, con énfasis en la infraestructura de red clave para el desarrollo de la I4.0 que es el 5G. En este escenario, Alemania enfrenta la particularidad de pertenecer a la Unión Europea, un bloque cada vez más dependiente de Estados Unidos y China respecto al desarrollo de las tecnologías 4.0, y al mismo tiempo de disponer de cierta autonomía que le permite liderar innovaciones en el campo de los sistemas ciberfisicos industriales. En su carácter de líder europeo, probablemente promueva la disputa por los datos industriales para preservar cierto margen de soberanía tecnológica. ${ }^{4}$

\section{Un enfoque desde América Latina}

En consonancia con las transformaciones socio-tecnológicas y productivas analizadas anteriormente, el contexto en el que se inscribe la discusión respecto al desarrollo de la I4.0 en América Latina reconoce una multiplicidad de condiciones estructurales que describen el punto de partida en el que se encuentran dichos países.

En primer lugar, se verifica un alto nivel de dependencia tecnológica que se traduce en la necesidad de importar la mayoría de las tecnologías requeridas para el desarrollo tecnológico e industrial, y una inserción dependiente en las cadenas globales de valor (Castillo et al 
2017). ${ }^{5}$ En paralelo, esta dependencia bloquea las posibilidades de generar capacidades locales para el desarrollo: "lo que estructura a las economías de la región, más que el hecho de ser primario-exportadoras, es quedar relegadas a un patrón secundario/terciario-importador de bienes industriales y servicios de alta intensidad innovativa" que tenderá a incrementar las brechas tecno-cognitivas entre países (Ramírez Gallegos y Sztulwark 2018:31).

En segundo lugar, se observa un atraso persistente en el desarrollo de capacidades tecnológicas y organizacionales para la adopción de TIC en el entramado productivo en general, y en el sector industrial en particular, que incrementa la ya existente brecha de productividad entre las economías desarrolladas y emergentes (Brixner et al 2019).

En tercer lugar, persiste una fuerte debilidad de los Sistemas Nacionales de Innovación (SNI) de los países latinoamericanos, caracterizada por el déficit de transferencia de tecnología entre los sectores de ciencia y tecnología (CyT) y los aparatos productivos, y la falta de sinergias generadas entre los diversos actores (Casas y Luna 2011; Arocena y Sutz 2014).

Por último, un déficit generalizado en la infraestructura tecnológica y la conectividad que se ve plasmado en una cobertura de redes $4 \mathrm{G}$ menor al 35\%, velocidad de la banda de ancha menor a $300 \mathrm{Kbps}$, velocidad de descarga por debajo de los $50 \mathrm{Mbps}$, un espectro asignado a servicios móviles en promedio de $365 \mathrm{MHz}$ (la mitad que los países desarrollados), y una muy baja densidad de sensores y robots por debajo del promedio mundial, que alcanza 66 robots por 10.000 trabajadores manufactureros (Castillo et al 2017: 561).

Estos aspectos, que definen el punto de partida para la I4.0 en América Latina, se encuentran condicionados por tres procesos en desarrollo que afectan el funcionamiento de la economía mundial. Por un lado, una tendencia global a la relocalización de las cadenas productivas a partir de la erosión de las clásicas ventajas comparativas establecidas sobre la base de la oferta de mano de obra barata, y un aumento de la importancia de la dotación local de factores tales como el capital humano, la infraestructura tecnológica, el costo energético, entre otros factores (Basco et al 2018). Este proceso conduce a que algunas empresas decidan relocalizar su producción, o ciertas actividades de sus procesos productivos, en el país o región de origen (Gray et al 2013).

Por otro lado, un proceso de descentralización de la producción bajo el modelo de manufactura distribuida que altera la composición tradicional de las cadenas globales de valor. Se trata de producir en proximidad al cliente y de forma personalizada. Basco et al (2018: 17) señalan que "se acorta la distancia entre el fabricante y el consumidor (...) se reducen intermediarios y se minimiza la posibilidad de crear valor mediante acumulación de inventarios/stocks". A la elaboración de productos manufacturados, se le añade la posibilidad de vender servicios y configurar de esta forma un producto-plataforma. 
Por último, dado que se requieren nuevas habilidades para la I4.0, se ampliarían las brechas de conocimiento entre las economías centrales y periféricas. Los sistemas de educación y los de ciencia, tecnología e innovación, cobran un rol central a la hora de generar capacidades tecnológicas aplicadas a la industria. La histórica dicotomía entre centro y periferia se afianza sobre la base de la formación de capital humano capaz de alimentar el proceso de digitalización de la industria. Las nuevas habilidades requeridas son consideradas híbridas (blandas y duras) y multidisciplinares. Se trata de conocimientos en matemática, ingeniería, informática, electrónica y el análisis de datos, pero también habilidades blandas como el pensamiento crítico y la creatividad (Basco et al 2018).

4.1. Características y trayectorias de los países potencialmente líderes en el desarrollo de la I4.0 en América Latina

De acuerdo a Sztulwark (2019) en las últimas décadas la lógica estructural del capitalismo experimentó ciertas transformaciones: las diferencias de especialización sectorial no desaparecieron pero fueron atravesadas por una forma de cadena que introdujo un corte al interior de los distintos sectores, a partir de distinguir entre países que realizan actividades de creación de conocimiento (innovación) y países que lo reproducen (producción). Bajo esta lógica, el cambio estructural consiste en "un cambio de posición en la estructura en el sentido de A (adoptante) $\rightarrow>$ D (desarrollador) en sectores de creciente potencial de acumulación” (Sztulwark 2019:17).

En relación con la I4.0, las principales economías del mundo se encuentran desplegando iniciativas tanto para desarrollar como para incorporar tecnologías 4.0 en los procesos productivos, como se observó en la sección anterior. En este esquema, para cambiar su posición en la estructura económica, los países latinoamericanos deberían aspirar a transformarse primero en adoptantes y luego en desarrolladores de dichas tecnologías. De lo contrario es probable que la brecha tienda a expandirse.

Si bien las transformaciones en el paradigma tecnoeconómico permitirían la inserción de ciertos sectores y empresas de países periféricos en los mercados mundiales, la posibilidad de capitalizar dicha oportunidad dependería de las capacidades industriales y tecnológicas previamente construidas (Gutman y Robert 2018; Brixner et al 2019). Por ello, quienes cuenten con mayores capacidades serán los que se hallen en mejores condiciones para desarrollar, producir e incorporar las tecnologías 4.0.

Siguiendo a Sztulwark (2019), el proceso de valorización tiende a producirse mucho antes que en la esfera de la reproducción de mercancías estandarizadas, y se desplaza hacia la creación de nuevos conocimientos. Al mismo tiempo, dado que en la actualidad se registra un proceso de desconcentración de la producción que convive con uno de centralización del comando, la entrada de países periféricos a la etapa de producción, desprovista de su 
participación en la etapa de concepción de nuevas técnicas productivas y diseño de nuevos productos, no implica una desconcentración del poder dentro de las cadenas globales.

En este complejo escenario es preciso preguntarse: ¿Cuáles son los desafios de los países latinoamericanos para adoptar los nuevos conocimientos y tecnologías que componen el universo 4.0? ¿Qué países son los que cuentan con mayores posibilidades de llevar esto a cabo?

En el presente trabajo se considera que México, Argentina y Brasil son los que cuentan con mayor potencial para desarrollar la I4.0 por al menos cuatro razones:

- Constituyen las economías con el PBI más elevado de la región. En 2018, el de Brasil fue u\$s 1,.869 billones, el de México u\$s 1,22 billones y el de Argentina u\$s 519 mil millones de USD. Las tres economías representaron el $62 \%$ del total regional (Banco Mundial, 2020).

- Son los tres países con mayor valor agregado del sector industrial en la región. En 2018, en México fue de u\$s 377 mil millones, en Brasil u\$s 344 mil millones de USD y en Argentina u\$s 119 mil millones. El valor agregado de la industria de los tres países seleccionados representa el 55\% del total regional (Banco Mundial, 2020).

- Cuentan con un porcentaje mayor de exportaciones de media-alta tecnología y tienen mayores capacidades tecnológicas (medida en gasto en $\mathrm{I}+\mathrm{D}$ como porcentaje del PBI y cantidad de patentes per cápita) con relación al resto de los países de la región (Schteingart et al 2019).

- A pesar de exhibir bajos niveles de la implementación de la I4.0, cada uno de los países evidencia un recorrido, aunque todavía incipiente y en algunos casos incierto, en el diseño de políticas públicas para impulsarla. ${ }^{6}$

A partir de la revisión de la literatura, es posible identificar una serie de características comunes respecto a las potencialidades y limitaciones para el desarrollo de la I4.0 en los países seleccionados (Cuadro $\mathrm{N}^{\circ} 3$ ). En primer lugar, entre los nichos sectoriales con potencialidades para impulsar su desarrollo, sobresale el sector automotriz, agropecuario, químico y aeroespacial (Brixner et al, 2019). También se destaca la presencia de grandes empresas multinacionales con capacidades de incorporar las tecnologías 4.0. Albrieu et 
al (2019), al analizar el grado de penetración de las tecnologías 4.0 en las empresas manufacturera, sostienen que tanto en Argentina como en Brasil, las grandes firmas son las que logran incorporar tecnologías de tercera generación y en algunos casos de cuarta generación. Además, se caracterizan por disponer de un equipamiento apto para hacer frente al cambio tecnológico y capacidades robustas para soportar las inestabilidades de la economía tanto doméstica como internacional. Constituyen mayoritariamente empresas exportadoras que integran distintas ramas de la industria (textil, alimentos procesados, maquinaria agrícola, siderurgia, etc.) e invierten mayor capital en tecnología e investigación y desarrollo que las firmas de menor tamaño.

Con relación a las limitaciones, también se identifican problemáticas compartidas entre los países de la región, como por ejemplo un déficit general de capital humano con habilidades y conocimientos necesarios para la digitalización de la industria, y una infraestructura y conectividad defectuosa (Castillo et al 2017; Brixner et al, 2019). En el caso argentino, se agrega el contexto macroeconómico que opera como un limitante específico, y se relaciona con tres factores asociados a la política económica implementada entre 2018 y 2019. En primer lugar, el endeudamiento con el Fondo Monetario Internacional (FMI) y los bonistas privados que impide acceder al crédito externo y obliga a reestructurar la deuda para salir del default. En segundo lugar, la inestabilidad cambiaria producto de las desregulación financiera y sus efectos sobre los costos de producción. Por último, las altas tasas de interés que dificultan el acceso al financiamiento para la inversión productiva. Estas deficiencias macroeconómicas constituyen un obstáculo concreto al desarrollo de la I4.0 en tanto impactan de forma negativa en el nivel de actividad económica y las posibilidades de crecimiento de las empresas industriales que demandan bienes y servicios tecnológicos, con énfasis en las PyMES.

En relación con las capacidades científico-tecnológicas, si se consideran indicadores básicos como el gasto en I+D en función del PBI (Gráfico $N^{\circ} 1$ ), la cantidad de patentes solicitadas por residentes (Gráfico $\mathrm{N}^{\circ} 2$ ), y la cantidad de investigadores dedicados a actividades de $\mathrm{I}+\mathrm{D}$ por millón de habitantes (Gráfico $\mathrm{N}^{\circ} 3$ ), se observa que son los tres países con mejor desempeño regional (Banco Mundial, 2020). Brasil es el que evidencia mayores capacidades científico-tecnológicas, en tanto exhibe un mejor desempeño en dos de los tres indicadores seleccionados; mientras que Argentina lidera la cantidad de investigadores dedicados a actividades de I+D por millón de habitantes, y se encuentra por encima de México en función del gasto en $\mathrm{I}+\mathrm{D}$, rubros en los que éste último muestra un desempeño incluso inferior a otros países latinoamericanos.

Las cifras alcanzadas los ubican muy por debajo de los países líderes: con relación al gasto en I+D como porcentaje del PBI, mientras que en 2017, en Brasil fue 1,27\%, en Argentina 0,54\% y en México 0,33\%; en Alemania fue 3,03\%, en Estados Unidos 2,81\%, y en China 2,14\% (Banco Mundial, 2020). 
Gráfico N¹: Gasto en I+D en función del PBI (en \%)

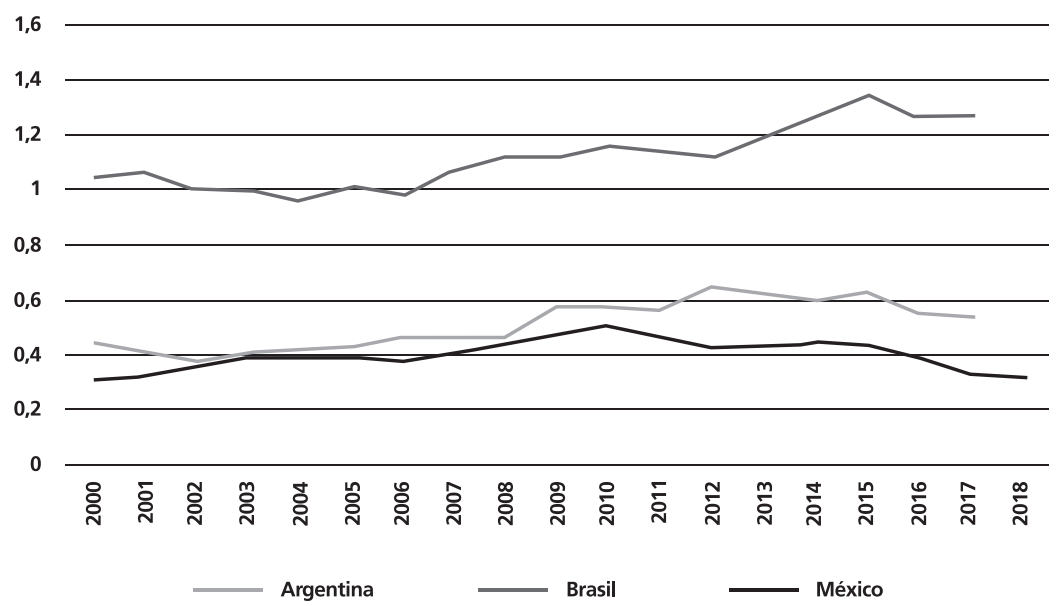

Fuente: elaboración propia en base a Banco Mundial (2020)

En lo que refiere a la solicitud de patentes por residentes, en 2017, en Brasil se solicitaron 5.480, en México 1.334 y en Argentina 393 (Banco Mundial, 2020). Como se observó en la sección 3, estas cifras los ubican a una distancia muy considerable respecto a los países líderes. Al analizar las tendencias, mientras que en Brasil y México la solicitud de patentes por residentes se incrementó de manera sostenida a partir del 2000, en Argentina se observa una caída entre 2005 y 2010, y un descenso entre 2016 y 2017, lo que indica una fluctuación más alta que el resto. 
Gráfico $\mathbf{N}^{\circ}$ 2: Solicitudes de patentes por residentes

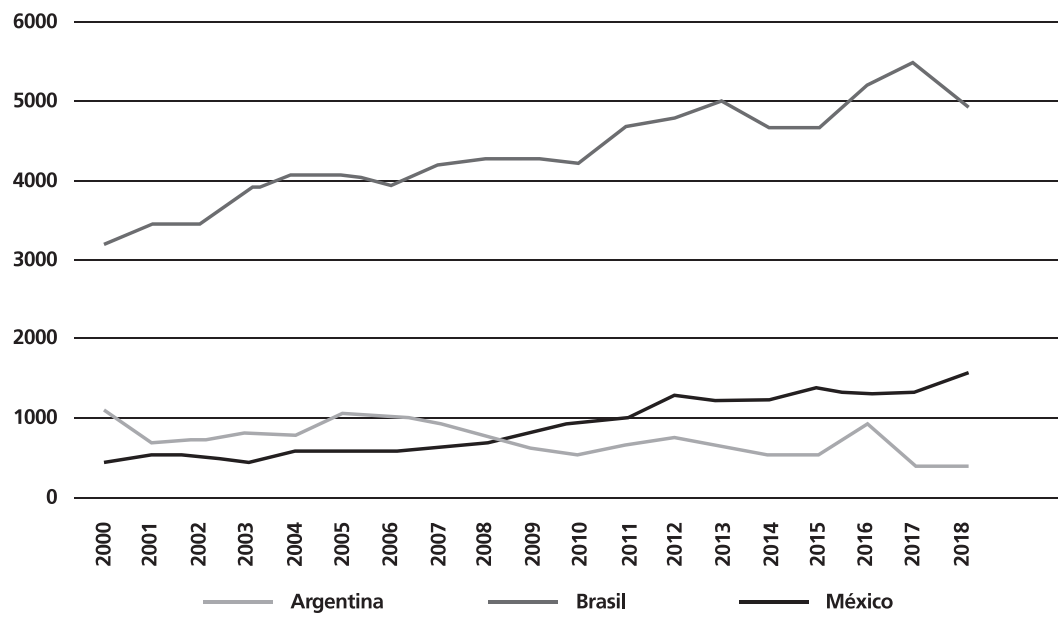

Fuente: elaboración propia en base a Banco Mundial (2020)

Por último, con relación a los investigadores dedicados a actividades de I+D por millón de habitantes, Argentina contó, en 2017, con 1192, Brasil, en 2014, con 888 y México, en 2013, con 252; mientras que Alemania contó, en 2017, con 5.003; Estados Unidos, en 2016, con 4.245; y China, en 2017, con 1.225 (Banco Mundial, 2020).

Gráfico N³: Investigadores dedicados a I+D (por millón de personas)

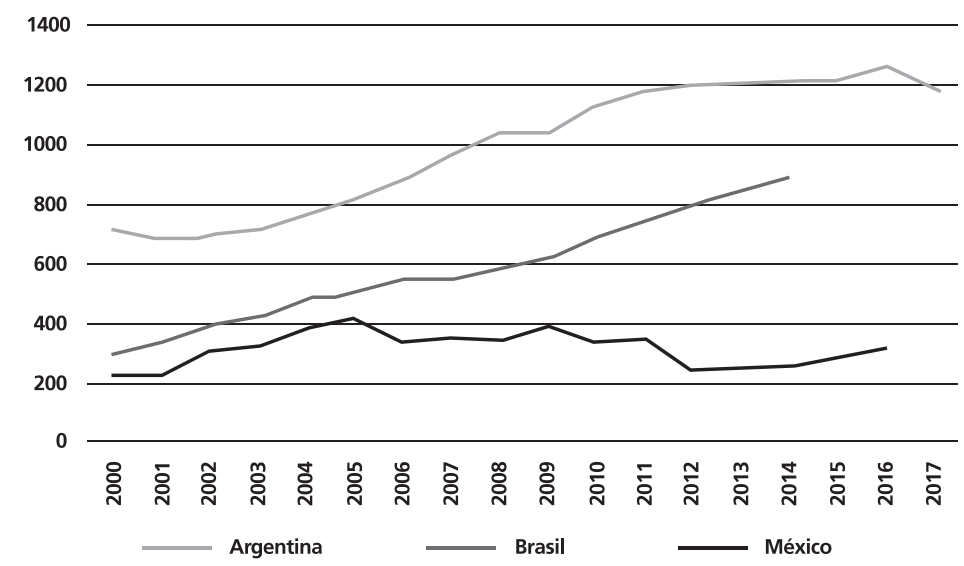

Fuente: elaboración propia en base a Banco Mundial (2020) 
Los datos expuestos reflejan un incremento en las capacidades científico-tecnológicas por parte de Brasil entre el 2000 y el 2015, con una desaceleración y cierto estancamiento a partir de 2015 y con una caída más pronunciada a partir de 2017 en el caso de las patentes por residentes. En el caso de Argentina, se registra un crecimiento sostenido de la inversión en I+D como porcentaje del PBI y en la cantidad de investigadores por millón de habitantes entre los años 2003 y 2015, lo que revela un fortalecimiento significativo del sistema de CyT durante este periodo, y un proceso de estancamiento y debilitamiento posterior al 2015. En el campo de las patentes por residentes, sin embargo, se advierte una merma entre 2005 y 2010, con fluctuaciones ascendentes y descendentes entre el 2010 y el 2018. Por el lado de México, tanto la inversión en I+D como porcentaje del PBI, como la cantidad de investigadores por millón de habitantes, señalan una marcada fluctuación con una tendencia decreciente, lo que podría indicar un deterioro general del sistema de CyT, con énfasis en el periodo que va de 2006 a 2012. En el caso de las patentes por residentes, se observa un crecimiento lento pero sostenido desde el año 2003 hasta el 2018. Este ritmo ascendente le permitió superar a Argentina en 2009 y parece mostrar una tendencia más pronunciada de crecimiento a partir del 2012.

A partir del análisis de estos indicadores, se puede señalar que tanto Brasil como Argentina lograron fortalecer el sistema de CyT entre los años 2003 y 2015, a diferencia de México que registró un nivel de volatilidad más alto, con periodos de claro descenso en el financiamiento del sistema científico. Si bien el fortalecimiento de las capacidades científico-tecnológicas no determina necesariamente la evolución de las políticas de promoción de la I4.0, es probable que condicione la formación de capital humano necesario para su desarrollo.

Por otra parte los tres países, a pesar de tener ciertas similitudes en su matriz productiva y capacidades científico-tecnológicas, ocupan posiciones diferentes en la división internacional del trabajo. ${ }^{7}$ Según Schteingart et al (2019), México forma parte del grupo de países ensambladores en tanto cuenta con capacidades tecnológicas bajas, pero exporta manufacturas de media-alta tecnología. De acuerdo con dicha clasificación, Brasil se encuentra en una posición intermedia entre el grupo de países ensambladores y países no innovadores primarizados. Esto quiere decir que su canasta exportable está compuesta mayoritariamente por manufacturas de bajo contenido tecnológico y productos primarios, pero dispone de una capacidad tecnológica media.Argentina forma parte de los países no innovadores primarizados, lo que implica que dispone de una baja capacidad tecnológica y exporta mayoritariamente productos primarios, derivados de recursos naturales y manufacturas de baja tecnología. 
Cuadro N³: Países potencialmente líderes en el desarrollo de la I4.0 en AL

\begin{tabular}{|c|c|c|c|c|c|}
\hline País & $\begin{array}{l}\text { Nichos } \\
\text { sectoriales }\end{array}$ & $\begin{array}{l}\text { Potencial de } \\
\text { implementación }\end{array}$ & Limitaciones & $\begin{array}{l}\text { Capacidades científico- } \\
\text { tecnológicas } \\
\text { (último año disponible) }\end{array}$ & $\begin{array}{l}\text { Tipo de inserción en la } \\
\text { división internacional } \\
\text { del trabajo }\end{array}$ \\
\hline México & $\begin{array}{l}\text {-Automotriz } \\
\text {-Aeroespacial } \\
\text {-Biotecnología }\end{array}$ & $\begin{array}{l}\text { Clústeres } \\
\text { tecnológicos } \\
\text { locales }\end{array}$ & $\begin{array}{l}\text {-Déficit de personal } \\
\text { especializado } \\
\text { - Déficit de } \\
\text { infraestructura y } \\
\text { conectividad }\end{array}$ & $\begin{array}{l}\text {-Gasto en I+D/PBI: } 0,49 \% \\
\text {-Solicitud de patentes por } \\
\text { residentes: } 1.310 \\
\text {-Investigadores por millón } \\
\text { de habitantes: } 252 \text { (2013) }\end{array}$ & Ensamblador \\
\hline Brasil & $\begin{array}{l}\text {-Aeroespacial } \\
\text {-Automotriz, } \\
\text {-Alimento } \\
\text {-Agropecuario } \\
\text {-Químicos }\end{array}$ & $\begin{array}{l}\text { Firmas locales } \\
\text { especializadas } \\
\text { en servicios } \\
\text { tecnológicos y } \\
\text { startups }\end{array}$ & $\begin{array}{l}\text {-Déficit de personal } \\
\text { especializado } \\
\text { - Déficit de } \\
\text { infraestructura y } \\
\text { conectividad }\end{array}$ & $\begin{array}{l}\text {-Gasto en I+D/PBI: } 1,27 \% \\
\text {-Solicitud de patentes por } \\
\text { residentes: } 5.200 \\
\text {-Investigadores por millón } \\
\text { de habitantes: } 888 \text { (2014) }\end{array}$ & Intermedio \\
\hline Argentina & $\begin{array}{l}\text {-Automotriz } \\
\text {-Alimentos } \\
\text {-Maquinaria } \\
\text { agrícola } \\
\text {-Químicos } \\
\text {-Petroquímico } \\
\text {-Energía }\end{array}$ & $\begin{array}{l}\text { Pymes locales } \\
\text { con capacidad } \\
\text { de desarrollar } \\
\text { baja/media } \\
\text { complejidad } \\
\text { tecnológica }\end{array}$ & $\begin{array}{l}\text {-Déficit de personal } \\
\text { especializado } \\
\text { - Déficit de } \\
\text { infraestructura y } \\
\text { conectividad } \\
\text {-Contexto } \\
\text { macroeconómico }\end{array}$ & $\begin{array}{l}\text {-Gasto en I+D/PBI: } 0,53 \% \\
\text {-Solicitud de patentes por } \\
\text { residentes: } 884 \\
\text {-Investigadores por millón } \\
\text { de habitantes: } 1.192(2017)\end{array}$ & $\begin{array}{l}\text { No innovador } \\
\text { primarizado }\end{array}$ \\
\hline
\end{tabular}

Fuente: Elaboración propia en base a Brixner, et al. (2019), Schteingart, et al. (2019), Castillo, et al (2017) y Banco Mundial (2020).

El Cuadro $N^{\circ} 3$ presenta una síntesis de las principales características de los tres países seleccionados con relación a sus limitaciones y potencialidades para el desarrollo de la I4.0 en la región.

\subsection{Políticas públicas para la promoción de la Industria 4.0 en América Latina: ¿hacia un modelo latinoamericano?}

Además de las diferencias y similitudes entre estos tres países en relación con su perfil productivo, sus capacidades tecnológicas y la posición que ocupan en la división internacional del trabajo, en la presente sección se analizan las iniciativas públicas destinadas a desarrollar la I4.0.

Como se señala al inicio de la sección anterior, el tema de la I4.0 ingresa en los últimos años a las agendas de gobierno de México, Argentina y Brasil y -aunque con avances todavía modestos- se inicia un camino de diagnóstico y diseño de políticas para su promoción (Cuadro $\mathrm{N}^{\circ} 4$ ).

México constituye el primer país de América Latina en diseñar una estrategia para el desarrollo de la I4.0 (Basco et al, 2018). En 2016 lanzó la iniciativa denominada Crafting the future: a roadmap for industry 4.0 in México, que surgió a partir de un proceso liderado por el Ministerio de Economía de la Nación en articulación con actores del sector privado y la academia, y representó el inicio de una estrategia consensuada para la transformación digital 
de la industria mexicana. El documento analiza las capacidades locales con relación a los recursos humanos e infraestructurales del país para avanzar en un camino de convergencia entre la industria manufacturera y las tecnologías 4.0 (Secretaría de Economía, 2016). La estrategia se estructura sobre la base de tres lineamientos: a) desarrollar clústeres tecnológicos que promuevan la especialización de las diferentes regiones del país; b) convertirse en un líder regional en el desarrollo de Internet de las Cosas (IoT), una de las tecnologías clave para la tecnificación de la industria manufacturera; c) incrementar la complejidad de su economía, para lo que se plantea establecer redes de colaboración entre el sector público, privado y académico, vincular la oferta y la demanda de bienes y servicios de la I4.0, entre otras acciones (Basco et al 2018; Secretaría de Economía 2016; Calatayud y Katz 2019).

Esta estrategia se enmarca en el Programa para el Desarrollo de la Industria del Software (PROSOFT), que a partir de su fusión con el Programa Fondos para Impulsar la Innovación, dieron lugar al Programa para el Desarrollo de la Industria del Software y la Innovación (PROSOFT) 4.0. La finalidad del instrumento es estimular el desarrollo de procesos innovadores en sectores prioritarios, fomentar el desarrollo tecnológico y la adopción de tecnologías que promuevan la generación y transferencia de conocimientos, promover la generación de capital humano especializado, y fomentar la implementación de las tecnologías 4.0 para la innovación en procesos y productos, y la digitalización de servicios (Diario Oficial, 2019). Para cumplir con estos objetivos, el Estado destina fondos no reembolsables que deben ser utilizados para la ejecución de proyectos presentados por los beneficiarios (sean empresas grandes o medianas, instituciones académicas o instituciones gubernamentales).

La estrategia mexicana cuenta con un modelo de gobernanza que incluye múltiples actores, coordinados por un Consejo Consultivo de Industria 4.0, un órgano multisectorial cuya función es la definición de objetivos y responsables, y tomar decisiones sobre las acciones a ejecutar para desarrollar la I4.0 en el país. Cuenta con ocho mesas de trabajo temáticas: ciberseguridad, infraestructura, alineación de política pública, automatización inteligente, educación y adopción tecnológica, costos de transición, financiamiento, y comercio electrónico (Secretaría de Economía, 2018).

Uno de los elementos destacados de la política mexicana es la creación de Centros de Innovación Industrial (CII), que consisten en espacios semi-públicos que tienen como objetivo la formación, especialización y certificación de capital humano, y la oferta de servicios especializados (Secretaría de Economía, 2019). Esta política busca generar sinergias entre empresas de un mismo sector o industria, y fomentar la transferencia de conocimientos. Para ello se crean infraestructuras semi-públicas autofinanciables que impulsan el desarrollo de proveedores, la consolidación de clústeres industriales, las cadenas de valor, el desarrollo de capital humano y las competencias de especialización para adoptar tecnologías tendientes a incrementar la productividad (Diario Oficial, 2019a). Entre 2016 y 2019 se financiaron 44 CII distribuidos en todo el territorio 
mexicano, que se especializan en distintos sectores: automotriz, TIC, aeroespacial, I4.0, IA, ciberseguridad, ciencia de datos, realidad aumentada, manufactura, entre otros. ${ }^{8}$.

En Argentina se lanzó en 2019 el Plan Industria Argentina 4.0 que busca promover las capacidades tecnológicas de las empresas por medio de la incorporación de tecnologías emergentes (uso de Big Data, IA, Impresión 3D, entre otras). Si bien todavía no se registran avances significativos, el Plan establece la creación de un Comité Ejecutivo 4.0 y un Consejo Asesor Industria 4.0 con el objetivo de elaborar un plan de trabajo y fortalecer redes institucionales de apoyo tecnológico. ${ }^{9}$ Otras iniciativas orientadas a promover la innovación tecnológica en PyMES industriales fueron desarrolladas por la Secretaría de Pequeñas y Medianas Empresas y Desarrollo Regional (SEPYME) y el Instituto Nacional de Tecnología Industrial (INTI), que ofrecen servicios de acompanamiento referidos a la capacitación y sensibilización de conceptos vinculados a la I4.0, asesoramiento técnico para la transformación digital, y subsidios para I+D+i para el desarrollo de nuevos productos y/o soluciones tecnológicas para el desarrollo digital, entre otros. Se trata de apoyo no sólo dirigido a las PyMES, sino también a cámaras empresarias y entidades del sector público. ${ }^{10}$ Se pueden mencionar algunos avances en el campo de la impresión 3D, un sector de la I4.0 que creció de forma significativa a partir del 2017 en el área de servicios de diseño, industria y salud (INTI 2019).

Como dato saliente de las políticas argentinas se observa la sanción de Ley $\mathrm{N}^{\circ} 27.506$ de 2020 que establece un Régimen de Promoción de la Economía del Conocimiento. Este instrumento, que reemplaza a la Ley del Software sancionada en 2004, incorpora nuevas actividades productivas al régimen de promoción, entre las que se encuentran los bienes y servicios orientados a la automatización y la producción que incluyan tecnologías de la I4.0. La orientación es otorgar beneficios fiscales a las empresas, de modo tal que encuentren incentivos para desarrollar actividades de $\mathrm{I}+\mathrm{D}$, realicen mejoras en la calidad de sus productos o servicios, capaciten a sus empleados y exporten. Además incorpora incentivos adicionales para la contratación de mujeres, personas con discapacidad, profesionales con posgrado en carreras de ingeniería, entre otros; y se plantea crear un Consejo Consultivo que se encargará de evaluar que los beneficiarios cumplan los requerimientos establecidos. Finalmente, se incluye la creación del Fondo Fiduciario para la Promoción de la Economía del Conocimiento (FONPEC) dirigido a las Micro, Pequeñas y Medianas Empresas con la finalidad de financiar actividades de capacitación y formación, apoyar inversiones productivas, financiar capital de trabajo, y fomentar la inserción comercial internacional de las empresas.

Por último, en Brasil la estrategia nacional de desarrollo de la I4.0 se centra en cuatro líneas de acción que incluyen a cinco entidades de gobierno: los Ministerios de Industria, Comercio y Servicios, Economía, Ciencia, Tecnología, Innovación y Comunicación, Hacienda y al Banco Nacional de Desarrollo (BNDES), un actor central en las políticas de desarrollo económico a lo largo de la historia. En primer lugar, se destaca la inversión en I+D en tecnologías 4.0 con énfasis en IoT, a través de líneas de financiamiento para la 
investigación y subsidios para startups abocadas al desarrollo digital. En este caso, el Ministerio de Ciencia, Tecnología, Innovación y Comunicación (MCTIC) implementa programas como Profuturo, la Estrategia Brasileña para la Transformación Digital, el Plan Nacional de IoT y la creación del FINEP. ${ }^{11}$ Una segunda línea de acción refiere a la alianza públicoprivada entre asociaciones empresariales, confederaciones, cámaras industriales, sindicatos, y el gobierno federal a través del Ministerio de Industria, Comercio y Servicios orientada a diseñar un Programa Nacional de Industria 4.0. La Agenda Brasilera para la Industria 4.0 constituye hasta el momento su avance más relevante. ${ }^{12}$ En tercer lugar, se identifican líneas de financiamiento específico para la adopción de tecnologías 4.0 en la industria, con énfasis en proyectos de innovación para el sector PyME a través del BNDES. Se trata de apoyo financiero para adquirir equipamiento y/o invertir en I+D. Por último, se destacan los incentivos específicos sectoriales, como el Programa Ruta 2030 orientado a la adopción intensiva de tecnologías 4.0 en el sector automotriz mediante facilidades impositivas y una mejora de la infraestructura de telecomunicaciones (Calatayud y Katz, 2019).

En el año 2019 se creó la Cámara Brasileña de Industria 4.0 que aglutina a la Confederación Nacional de Industria (CNI) y a otras asociaciones y federaciones de empresas industriales del país, al Sindicato Nacional de las Empresas de Telefonía y de Servicios Móvil Celular y Personal (SindiTelebrasil), la Asociación Brasileña de Internet Industrial (ABII) y en su directorio participa el MCTIC y el Ministerio de Economía (ME), además del BNDES. El plan de acción 2019-2022 incluye cuatro ejes asociados a detectar nichos con mayor potencial de desarrollo tecnológico dentro de la industria, avanzar en la formación de capital humano en habilidades de la I4.0, impulsar las cadenas de valor de la industria 4.0 con énfasis en la participación de las PyMES en los distintos encadenamientos productivos, y actualizar y mejorar la regulación, normalización técnica e infraestructura tecnológica (MCTIC, 2019).

La experiencia mexicana pone en evidencia a búsqueda por impulsar desde el Estado, en articulación con actores académicos y empresarios, una estrategia destinada a la transformación digital de la industria y el desarrollo de capacidades para desarrollar tecnologías 4.0 en el país. En consonancia con las iniciativas desarrolladas por los tres países líderes, se observa un esfuerzo por vincular a los actores del sistema de CyT con las empresas, con el objetivo de promover el desarrollo de clústeres, y el desarrollo de capital humano especializado.

En Argentina, como rasgo general se observa una falta de estímulos para la vinculación de los actores del sistema de ciencia, tecnología e innovación, y con otros sectores productivos. Por el contrario, el principal estímulo para promover las actividades intensivas en conocimiento seleccionadas es aliviar la carga fiscal; lo que lo diferencia de la experiencia internacional donde se registran esfuerzos por articular a los actores que componen los sistemas de innovación (Erbes et al 2019). 
En el caso de Brasil, una de las principales limitaciones de las políticas se encuentran asociadas a la dificultad de coordinar y complementar instrumentos de políticas pública diferentes (subsidios, elaboración de una agenda de trabajo, cooperación pública-privada, créditos, etc.) que incluyen diversos actores sociales como: organismos públicos, asociaciones empresarias, sindicatos, cámaras industriales, entre otros. Esta situación conduce a la falta de claridad respecto a qué entidad estatal es la responsable de la política de I4.0 en el país, la duplicación de esfuerzos e iniciativas que podrían estar integradas en una sola propuesta, e incluso a la competencia entre programas, lo cual dilapida recursos, genera conflictos interministeriales y desorienta al sector privado (Calatayud y Katz 2019).

Del análisis de las políticas públicas en los tres países se desprende que comparten un diagnóstico general asociado al déficit de incorporación de tecnologías 4.0 al sistema productivo, escasez de capital humano especializado en áreas como Big Data e IoT, y un desequilibrio en la distribución de capacidades tecnológicas a nivel territorial. A raíz de este diagnóstico, se identifican ciertos rasgos comunes en los instrumentos propuestos, como los estímulos otorgados para la innovación mediante exenciones impositivas y/o líneas de financiamiento en sectores estratégicos.

A partir del recorrido propuesto, se observa que México orienta su estrategia hacia la conformación de redes multiactorales por medio del estímulo a clústeres tecnológicos en áreas asociadas a la I4.0 en distintas regiones del país. Asimismo, prioriza fuertemente la especialización de capital humano en áreas prioritarias. Su objetivo es constituirse en un líder regional en el campo de la I4.0, tanto en su desarrollo como su adopción en la industria. En Argentina el Plan Nacional Industria Argentina 4.0 se orienta a la digitalización e informatización de la producción. Sin embargo, como se señaló anteriormente, este plan no registra avances significativos, y el instrumento que está siendo tratado en el Congreso de la Nación se focaliza en otorgar exenciones impositivas a las empresas productoras de tecnologías 4.0, pero no establece incentivos hacia la conformación de redes como muestra la experiencia internacional. En el caso de Brasil, recién en el 2019 se avanzó con la conformación de una alianza públicoprivada de carácter federal para dinamizar la agenda de transformación digital de la industria y se creó la Cámara Brasileña para la Industria 4.0 que agrupa a los actores involucrados en las políticas de desarrollo de la I4.0. Por otro lado, en 2019 también se aprobó la creación del Plan Nacional de IoT como parte de la Estrategia Brasilera de Transformación Digital que se encuentra orientado a financiar y promover el desarrollo de startups abocadas al desarrollo de soluciones tecnológicas en el rubro de IoT. Los avances son modestos dada la coyuntura actual de la pandemia del COVID-19 que afecta de forma notoria la actividad industrial y la implementación de políticas públicas para el desarrollo productivo. 
Cuadro N4: El desarrollo de la I4.0 en México, Argentina y Brasil

\begin{tabular}{|c|c|c|c|}
\hline País Año & Principales iniciativas & Orientación general & Acciones \\
\hline $\begin{array}{l}\text { México } \\
2016\end{array}$ & $\begin{array}{l}\text { Mapa de ruta Industria } 4.0 \\
\text { PROSOFT e Innovación }\end{array}$ & $\begin{array}{l}\text { - Transformar a México en líder regional en } \\
\text { soluciones digitales y Big Data. } \\
\text {-Fomentar el desarrollo tecnológico y la } \\
\text { adopción de tecnologías que promuevan la } \\
\text { generación y transferencia de conocimientos. } \\
\text { - Promover la generación de capital humano } \\
\text { especializado. } \\
\text { - Promoción de clústeres sobre las capacidades } \\
\text { territoriales existentes. } \\
\text {-Formación de redes de innovación. }\end{array}$ & $\begin{array}{l}\text { - Creación del Consejo Consultivo de } \\
\text { Industria } 4.0 . \\
\text { - Financiamiento de proyectos } \\
\text { mediante aportes no reembolsables. } \\
\text { - Creación y fortalecimiento de } \\
\text { Centros de Innovación Industrial. }\end{array}$ \\
\hline $\begin{array}{l}\text { Argentina } \\
2019\end{array}$ & $\begin{array}{l}\text { Plan Nacional Industria } \\
\text { Argentina 4.0 (Resolución } \\
\text { Conjunta 1/2019 - RESFC- } \\
\text { 2019-APN-MPYT) } \\
\text { Régimen de Economía del } \\
\text { Conocimiento (Ley 27.506) }\end{array}$ & $\begin{array}{l}\text { - Favorecer la competitividad de la industria } \\
\text { nacional mediante la incorporación de } \\
\text { tecnologías digitales. } \\
\text { - Beneficios impositivos y acceso a crédito fiscal } \\
\text { para empresas del rubro I4.0. } \\
\text { - Instrumentos de política pública para } \\
\text { incrementar el empleo en la industria } 4.0 \text {. }\end{array}$ & $\begin{array}{l}\text {-Creación del Consejo Asesor } \\
\text { Industria 4.0 } \\
\text { - Creación del Comité Ejecutivo 4.0. } \\
\text {-Plataforma digital Industria Argentina 4.0. } \\
\text { - Creación de la Dirección de la } \\
\text { Industria } 4.0 \text { (INTI) } \\
\text { - Régimen de Promoción de la } \\
\text { Economía del Conocimiento }\end{array}$ \\
\hline $\begin{array}{l}\text { Brasil } \\
2019\end{array}$ & $\begin{array}{l}\text { Agenda Brasilera para la } \\
\text { Industria } 4.0 \\
\text { Estrategia Brasileña para la } \\
\text { Transformación Digital } \\
\text { Plan Nacional de IoT } \\
\text { Programa Ruta } 2030\end{array}$ & $\begin{array}{l}\text {-Desarrollo de la I4.0 en el marco de una } \\
\text { estrategia nacional de innovación. } \\
\text {-Alianza público-privada para el desarrollo de } \\
\text { la I4.0. } \\
\text { - Adopción de tecnologías } 4.0 \text { en sectores } \\
\text { productivos con potencial de desarrollo. } \\
\text {-Promoción de la innovación tecnológica en el } \\
\text { sector PyME industrial. } \\
\text { - Financiamiento a startups de tecnología. } \\
\text { - Mejora de la infraestructura de } \\
\text { telecomunicaciones. }\end{array}$ & $\begin{array}{l}\text {-Cámara Brasileña de Industria } 4.0 \\
\text {-Creación del Fondo de Promoción } \\
\text { de la Investigación y financiamiento de } \\
\text { startups en tecnologías } 4.0 \text { (FINEP) } \\
\text {-Créditos para equipamiento e I+D } \\
\text { para Pymes industriales a través del } \\
\text { BNDES }\end{array}$ \\
\hline
\end{tabular}

Fuente: Elaboración propia

\section{Reflexiones finales}

Sobre la base de las limitaciones registradas en los países potencialmente líderes de la I4.0 en América Latina, como la baja digitalización de su estructura industrial, las bajas capacidades científico-tecnológicas, y el déficit generalizado respecto a la formación de capital humano, se identifican cuatro grandes desafíos que permitirían delinear un modelo latinoamericano de I4.0. Como se desprende del análisis anterior, si bien los tres países comparten un diagnóstico similar respecto a las limitaciones y desafíos existentes, el incipiente desarrollo de las políticas públicas y sus enfoques divergentes, no permiten dar cuenta todavía de la existencia de un modelo latinoamericano.

En primer lugar, el desafio de las políticas diferenciadas: supone definir áreas específicas para el desarrollo científico-tecnológico que no se lleven a cabo bajo un modelo de derrame de capacidades tecnológicas que atente contra las posibilidades de cambio estructural en la matriz productiva. La transversalidad entre sectores de la economía y la convergencia en la aplicación productiva de las tecnologías 4.0 requiere esfuerzos estatales que consideren al conjunto de los actores socio-productivos. Albrieu et al (2019) 
identifican que las principales limitaciones de las empresas medianas o pequeñas de Argentina para poder escalar hacía un uso intensivo de tecnologías digitales refiere a la falta de financiamiento, la cultura organizacional de las empresas, el desconocimiento de estas tecnologías, y un déficit muy pronunciado en la inversión en investigación y desarrollo y capital fijo. Sin embargo, existe un grupo muy reducido de firmas que se encuentra en una posición mucho más cercana al cambio tecnológico propio de la I4.0. Se trata de las empresas más grandes, con un fuerte perfil exportador, que invierten en tecnología aplicada a los procesos productivos, en I+D y contratan servicios de tecnología digital provistos por grandes compañías. En la medida que la agenda de política pública comprenda las diferentes necesidades del sector productivo, se torna más factible que el proceso de digitalización opere de forma transversal en los distintos sectores de la economía e incluya la heterogeneidad de las unidades productivas.

En segundo lugar, el desafio de la institucionalización: refiere a la formulación de planes nacionales de promoción de la I4.0 que articulen instrumentos heterogéneos consensuados con múltiples actores: incubadoras de startups, subsidios en $\mathrm{I}+\mathrm{D}$, fortalecimiento del sector de CyT, formación de clústeres y entornos innovadores, inyección de la demanda para sectores tecnológicos estratégicos (economía del espacio, energías renovables, etc.), conformación de redes de colaboración público-privadas, implementación de proyectos de cooperación internacional, entre otras. La formación de organismos estatales dotados de financiamiento y abocados a la coordinación de las distintas herramientas, y la interacción entre diversos actores (gobiernos locales, universidades y/o centros de investigación, empresas, cooperativas y organizaciones de la sociedad civil) podría constituir un factor de aliento para garantizar la sostenibilidad de las estrategias de desarrollo tecnológico y productivo. Se trata también de impulsar instrumentos que atiendan tanto a la oferta de la Industria 4.0 -programas de investigación, fortalecimiento de la industria proveedora nacional, fondos semillas, capitales de riesgo, líneas de financiamiento, facilidades para la creación de empresas, entre otros- como a la demanda -crédito tributario a la innovación, financiamiento para equipamiento e infraestructura tecnológica, programa de compras públicas, centros de extensión tecnológica, entre otras herramientas- (Castillo et al, 2017). ${ }^{13}$ Si bien algunas de las políticas analizadas dan cuenta de este abordaje, es preciso avanzar en mayores niveles de institucionalización de modo que puedan ser instrumentos que se sostengan en el tiempo.

En tercer lugar, el desafio de la transferencia de conocimiento: implica reforzar el vínculo entre industria y universidad para que el conocimiento generado en la academia pueda contribuir a mejorar los procesos productivos, e integrándola en procesos de desarrollo mediante la interacción entre empresas y gobiernos a través de la creación de conocimiento, el desarrollo de tecnología y la formación de personas (Codner 2017). Si bien las universidades pueden operar en contextos de bajo desarrollo industrial, con poca absorción de los resultados de la investigación, existe el desafio de avanzar en una mayor vinculación mediante la generación 
de agendas complementarias con los entramados productivos locales para nutrirlos de capacidades de absorción de conocimiento generado por los grupos locales (Codner et al 2012), reconociendo que "los problemas locales pueden ser resueltos con soluciones locales" (Codner 2017: 56). El fenómeno de conocimiento encapsulado identificado por Feldman (2018), que refiere a las dificultades para transferir conocimiento del sector de CyT al sector productivo -observado en el caso específico del sector del software y los servicios informáticos (SSI) - se encuentra asociado a la falta de confianza técnica (Casas y Luna 2011), la tensión y desencuentro entre una racionalidad mercantil (maximización de la ganancia) y la racionalidad científica (producción de conocimiento); y lo que Di Meglio (2018) denomina dimensión organizacional, vinculada a las deficiencias institucionales internas de las universidades (falta de dirección y liderazgo por parte de directivos, déficit o falta de capacitación de las áreas encargadas de la vinculación tecnológica, y una baja propensión a la innovación en los métodos y estrategias de interacción con el sector productivo) constituyen algunos obstáculos recurrentes en los sistemas de ciencia y tecnología de América Latina (Casas 2001; Arocena y Sutz 2014; Romero Muñoz, 2008; Saavedra García 2009).

El desarrollo de estos vínculos a través de la participación activa del Estado alimentaría la conformación de entornos innovadores en distintas regiones de los territorios nacionales. El modelo mexicano de promoción de clústeres tecnológicos como factor de estímulo a la formación de redes de conocimiento constituye una oportunidad para explorar las posibilidades de ser replicado en el caso argentino y brasilero. Gutman, Gorenstein y Robert (2018), con relación a la experiencia de los clústeres de alta tecnología en Argentina, señalan que su formación se encuentra estrechamente ligada a las políticas de ciencia y tecnología, a las orientaciones macroeconómicas, y a los modelos políticos y económicos vigentes. Además, existirían ciertas precondiciones necesarias pero no suficientes para que se puedan desarrollar con éxito en los territorios: contar con infraestructuras locales de ciencia y técnica, presencia de universidad públicas y centros de investigación dedicados a la formación de capital humano, un rol activo de las incubadoras de base tecnológica, y políticas públicas implementadas en los distintos niveles territoriales tanto sectoriales como de transferencia tecnológica.

Por último, el desafio del salto tecnológico: consiste en la elaboración de estrategias de largo plazo que le permitan a los países latinoamericanos, no sólo mejorar los procesos productivos y diseñar nuevos bienes y servicios intensivos en conocimiento, sino también aspirar a transformarse en desarrolladores de tecnologías 4.0. Romper la dependencia tecnológica supone dar el salto de adoptante a desarrollador tecnológico, para lo cual la formulación e implementación de una política educativa y de innovación tecnológica centrada en la formación de competencias para la I4.0 constituye un punto de partida relevante. Como señala Piketty (2014: 88), "Los países más pobres alcanzan a los más ricos en la medida en que logran llegar al mismo nivel de conocimiento tecnológico, de calificaciones, de educación”. 
En línea con lo que señalan Schteingart et al (2019), el debate en torno al desarrollo industrial de las economías periféricas, muestra la relevancia de una estrategia de fortalecimiento de las políticas industriales y de ciencia y tecnología por sobre las estrategias de desregulación y apertura de la economía, como herramienta para escalar posiciones en las cadenas globales de valor. Como afirman Robert y Moncaut (2020: 39), no existen "trayectorias inevitables sino caminos alternativos de la organización de la producción y de la producción de conocimiento que llevan a diferentes escenarios en materia de cambio tecnológico".

Siguiendo la línea de razonamiento de Ros Bosch (2015) afrontar los desafíos señalados abriría una ventana de oportunidad para salir de la trampa del bajo desarrollo tecnológico: un círculo vicioso entre bajas o medias capacidades tecnológicas, reflejadas en una baja inversión pública y privada en I+D y educación, y un bajo nivel de desarrollo económico evidenciado en un lento crecimiento coincidente con altos niveles de desigualdad.

La irrupción de la pandemia del COVID-19 a principios del 2020 impone nuevos desafios tanto para hacer frente a las necesidades y demandas de los distintos sectores productivos como para planificar políticas públicas que se orienten a mejorar las capacidades tecnológicas de las empresas industriales, promover el desarrollo de la innovación socio-tecnológica y formar el capital humano requerido para el desarrollo de la I.40 en América Latina. Aparecen nuevas limitaciones vinculadas al deterioro de los indicadores económicos más relevantes a nivel nacional, regional e internacional asociados a la caída de la actividad económica, el consumo, la inversión y el comercio, que introducen algunas interrogantes: ¿Cuál será la magnitud de la crisis y de qué modo afectará a la industria en el corto, mediano y largo plazo? ¿Cuál es el rol que puede ejercer la I4.0 en la construcción del orden económico post pandemia? ¿Se puede constituir en un factor dinamizador del desarrollo y la reactivación económica mundial? ¿Cómo quedará posicionada América Latina en este nuevo escenario? ¿Qué políticas son necesarias para que no se incrementen aún más las desigualdades existentes respecto a los países centrales? ¿La crisis económica multiplicará los obstáculos para el desarrollo de la I4.0 en la región, o por el contrario actuará como un factor de aceleración del cambio tecnológico? 
${ }^{1}$ La empresa red característica del informacionalismo (Castells 2001) se mantiene vigente, pero emerge una nueva forma de organización de la producción mediada por plataformas, centrada en la gestión algorítmica de las firmas (Fernández-Macías 2018 en Zukerfeld 2020).

${ }^{2}$ Schteingart et al (2019) consideran que los países innovadores industriales son aquellos que exportan mayoritariamente manufacturas de alto contenido tecnológico y presentan una alta capacidad tecnológica basada en niveles elevados de inversión en I+D como porcentaje del PBI y patentes per cápita. En esta categoría se encuentran países como Estados Unidos, Alemania, Japón, Francia, Corea del Sur, Suecia, Israel, Finlandia, entre otros.

${ }^{3}$ Por tal motivo, a pesar del desarrollo evidenciado en los últimos años, Schteingart et al (2019) consideran a China como un país innovador industrial pero muy cercano a los países considerados ensambladores, es decir, aquellos que exportan manufacturas de medio y alto contenido tecnológico pero presentan capacidades tecnológicas medias o bajas. Además, los autores ubican a este país dentro de los países considerados intermedios, un grupo integrado por distintos tipos de países (innovador primarizado, innovador industrial, ensamblador, y primarizado no innovador) que tienen como característica común el hecho de compartir índices de capacidades tecnológicas cercanos al promedio. ${ }^{4}$ Se trata de los datos generados a través del "Internet industrial de las cosas" (Cuenca 2020) o de las llamadas "plataformas industriales" (Srnicek 2018).

${ }^{5}$ Como afirman Dalle, Fossati y Lavopa (2013), la mera inserción de las empresas de un país en cadenas globales de valor no significa un avance en el desarrollo económico. Su éxito dependerá de la ubicación que tengan dichas empresas en las mismas, ya que ésta es la que determina los beneficios obtenidos.

${ }^{6}$ Se considera un nivel bajo de implementación dado que menos del 10\% de las empresas industriales cuentan con tecnologías de cuarta generación, uso de TIC de forma integrada, conectada e inteligente, y retroalimentación de información sobre operación para apoyar la toma de decisiones (Albrieu et al 2019).

${ }^{7}$ Para realizar la tipología sobre la inserción de los países en la división internacional del trabajo, Schteingart et al (2019) cruzan dos variables: a) ExpoTEC que refiere al grado de contenido tecnológico de las exportaciones; y b) capacidades tecnológicas basadas en la inversión en I+D como porcentaje del PBI y patentes per cápita. Los indicadores utilizados en este trabajo para caracterizar las capacidades científico-tecnológicas difieren de la categoría construida en el citado estudio para medir capacidades tecnológicas, en tanto se toma el total de solicitudes de patentes por residentes y se incorpora la cantidad de investigadores por millón de habitantes, a los fines de obtener información adicional relevante sobre un factor fundamental para el desarrollo de la I4.0 como son los recursos humanos altamente formados.

${ }^{8}$ Disponible en: t.ly/muQY. Fecha de consulta: 23/07/2020.

${ }^{9}$ Disponible en: t.ly/G28J. Fecha de consulta: 23/07/2020.

${ }^{10}$ Disponible en: https://url2.cl/UiqUf. Fecha de consulta 22/07/2020.

${ }^{11}$ Disponible en: https://url2.cl/X8enu. Fecha de consulta: 18/07/2020.

${ }^{12}$ Se identifican cinco áreas prioritarias del desarrollo I4.0: IoT, Manufactura aditiva, IA, Biología sintética, y sistemas ciberfisicos. Disponible en: https://url2.cl/QKZyx. Fecha de consulta: 19/07/2020.

${ }^{13}$ Castillo et al (2018: 570) consideran a las políticas de oferta como: "creación de capacidades tecnológicas de la Industria 4.0" y las de demanda como: "desarrollo de competencias digitales dentro de las empresas". 


\title{
Referencias bibliográficas
}

\author{
Albrieu, Ramiro, Basco, Ana I., Brest López, Caterina, De Acevedo, Belisario, \\ Peirano, Fernando, Rapetti, Martin, y Vienni, Gabriel (2019) Travesía 4.0: hacia la \\ transformación industrial argentina. Buenos Aires: BID-INTAL.
}

Arocena, Rodrigo y Sutz, Judith (2014) "Innovación y democratización del conocimiento como contribución al desarrollo inclusivo”. En Gabriela Dutrénit y Judith Sutz (eds.). Sistemas de innovación para un desarrollo inclusivo. La experiencia latinoamericana. México: Foro Consultivo Científico y Tecnológico.

Artemis Industry Association (2016) Artemis Strategic Research Agenda 2016. Netherlands: CPLS.

Banco Mundial (2020) Datos de libre acceso del Banco Mundial. https://datos. bancomundial.org/ accesado el 7 de febrero de 2020.

Basco, Ana I., Beliz, Gustavo, Coatz, Diego y Garnero, Paula (2018) Industria 4.0: fabricando el futuro, Buenos Aires: BID-INTAL.

Baum, Gabriel (2015) Hacia una nueva ola en la revolución de las tecnologías de la información y las comunicaciones. Ministerio de Ciencia, Tecnología e Innovación Productiva. Recuperado de <https://bit.ly/35KgQst>

Brixner, Cristian, Isaak, Paula, Mochi, Silvina, Ozono, Maximiliano y Yoguel, Gabriel (2019) Industria 4.0: ¿intensificación del paradigma tic o nuevo paradigma tecnoorganizacional? Buenos Aires: CIECTI.

Brynjolfsson, Erik y McAffe, Andrew (2016) La Segunda Era de las Máquinas. Trabajo, progreso y prosperidad en una época de brillantes tecnologías. Buenos Aires: Editorial Temas.

Casalet, Mónica (2018) La digitalización industrial: un camino hacia la gobernanza colaborativa. Estudios de casos. Documentos de Proyectos (LC/TS.2018/95). Santiago de Chile: CEPAL.

Casas, Rosalba y Luna, Matilde (2011) 'De redes y espacios de conocimiento: Significados conceptuales y de política”. En Hernández, Antonio y Kreimer, Pablo (eds.). Estudio Social de la Ciencia y la Tecnología desde América Latina. Bogotá: Siglo del Hombre Editores.

Castillo, Mario, Gligo, Nicolo, y Rovira, Sebastián (2017) "La política industrial 4.0 en América Latina”. En Cimoli, Mario; Castillo, Mario; Porcile, Gabriel y Stumpo, Giovani (eds.). Politicas industriales y tecnológicas en América Latina. Santiago de Chile; CEPAL. 
Castells, Manuel (2001) La era de la información. Economía, sociedad, y cultura.Vol.1, 2 y 3. Madrid: Editorial Alianza.

Calatayud, Agustina y Katz, Raúl (2019) Cadena de suministro 4.0: mejores prácticas internacionales y hoja de ruta para América Latina. Biblioteca Felipe Herrera del Banco Interamericano de Desarrollo (BID).

Chung, Mihyun y Kim, Jaehyoun (2016) “The Internet Information and Technology Research Directions based on the Fourth Industrial Revolution". KSII Transactions on Internet and Information Systems Journal, 10(3), DOI <10.3837/tiis.2016.03.020>

CNI-MEI (2018) Industria 2027. Síntese dos resultados. Construindo o futuro da indústria brasileira.IEL-Instituto Euvaldo Lodi.Brasilia.Recuperado de $<$ https://bit.ly/382YNPM $>$

Codner, Darío, Becerra, Paulina, Díaz, Alberto (2012) Blind Technology Transfer or Technological Knowledge Leakage: a Case Study from the South. J. Technol. Journal of Technology Management \& Innovation, 7(2), 184-195.

Codner, Darío (2017) Elementos para el diseño de políticas de transferencia tecnológica en universidades. Redes, 23 (45), 49-61.

Dalle, Demián; Fossati, Verónica; y Lavopa, Federico (2013) "Política industrial: ¿el eslabón perdido en el debate de las Cadenas Globales de Valor?”. Revista Argentina de Economía Internacional, 2, 3-16.

Deloitte (2017) Manufacturing USA. A Third-Pary Evaluation of Program Design and Progress. Recuperado de $<$ t.ly/31KG $>$

Diario Oficial de México (2019) Reglas de operación del Programa para el Desarrollo de la Industria de Software (PROSOFT) y la Innovación para el ejercicio fiscal de 2020. Recuperado de <https://prosoft.economia.gob.mx/doc/ROP\%20PROSOFT\%202020.pdf>

Diario Oficial de México (2019a) Reglas de operación del Programa para el Desarrollo de la Industria de Software (PROSOFT) y la Innovación para el ejercicio fiscal de 2019. Recuperado de <https://www.gob.mx/cms/uploads/attachment/file/440337/ro2019prosoft_1_.pdf>

Digital Transformation Monitor (2017) Germany: Industrie 4.0. European Union. Recuperado de $<$ t.ly/FexW $>$ 
Di-Meglio, Fernanda (2018) "Factores que favorecen la vinculación de las universidades con los sectores productivos en Argentina". Revista Iberoamericana de Educación Superior (RIES), 9(24), 58-80.

Erbes, Analía, Gutman, Graciela, Lavarello, Pablo; y Robert, Verónica (2019) "Industria 4.0: oportunidades y desafios para el desarrollo productivo de la provincia de Santa Fe”. Documentos de Proyectos (LC/TS.2019/80). Santiago de Chile: CEPAL.

Ezell, Stephen (2016) A Policymaker's Guide to Smart Manufacturing. Information, Technology and Innovation Foundation. Recuperado de $<$ t.ly/zB1b $>$

Federal Ministry for Economic Affairs and Energy (2016) Digitization of Industrie - Plattform Industrie 4.0. Progress Report. April 2016. Recuperado de <t.ly/zB1b>

Feldman, Patricio (2018) Procesos de innovación socio-tecnológica en el sector de Software y Servicios Informáticos (SSI) de la Ciudad de La Plata: redes, actores y políticas públicas. Tesis para obtener el grado de Doctor en Ciencias Sociales por la Universidad de Buenos Aires.

Finquelievich, Susana (2019) “Que no cunda el pánico. Habemus trabajo”. Revista Telos: Cuadernos de Comunicación e Innovación. Madrid. Recuperado de <https://bit.ly/385Y4O3>

Galliano, Alejandro (2020) ¿Por qué el capitalismo puede soñar y nosotros no?: Breve manual de las ideas de izquierda para pensar el futuro. Buenos Aires: Siglo XXI Editores.

Gray, John, V., Skowronski, Keith, Esenduran, Gökçe, Rungtusanatham, Johnny (2013) "The reshoring phenomenon: what supply chain academics ought to know and should do". Journal of Supply Chain Management, 49(2), 27-33. Recuperado de <https://onlinelibrary.wiley.com/doi/abs/10.1111/jscm.12012>

Grossman, Gene y Rossi-Hansberg, Esteban (2008) “Trading Task: A Simple Theory of offshoring". The American Economic Review, 98(5), 78-97.

Gutman, Graciela, Gorenstein, Silvia y Robert, Verónica (Coord.) (2018) Territorios y nuevas tecnologías. Desafíos y oportunidades en Argentina. Ciudad Autónoma de Buenos Aires: Punto Libro.

Instituto Nacional de Tecnología Industrial (2019) Fabricación de impresoras 3D en Argentina. Ministerio de Producción y Trabajo. Presidencia de la Nación. Buenos Aires, Argentina. Recuperado de <https://url2.cl/BagcN $>$ 
Kagermann, Henning, Helbig, Johannes y Wahlster, Wolfgang (2013)

"Recommendations for implementing the strategic initiative industrie 4.0, Securing the future of German manufacturing industry". Final report of the Industry 4.0. Berlin: Forschungsunion. Recuperado de $<$ https://bit.ly/2FLT8S9 $>$

Klingenberg, Cristina y Do Vale Antunes Jose, A. (2017). "Industry 4.0: What Makes it Revolution”. Inspiring Operations Management, 1(5). Recuperado de < https://bit.ly/2TuL0Of $>$

Lasi, Heiner, Fettke, Peter, y Kemper, Hans (2014) "Industry 4.0, Application-Pull and Technology-Push as Driving Forces for the Fourth Industrial Revolution”. Business E Information Systems Engineering, 6(4). DOI <https://doi.org/10.1007/s12599-014-0334-4>

Ma, Huimin, Wu, Xiang, Yan, Li, Huang, Han, Xiong, Jie, Zhang, Jinlong (2018) "Strategic Plan of Made in China 2025 and Its Implementation", Analyzing the Impacts of Industry 4.0 in Modern Business Environments. IGI Global. Recuperado de <t.ly/3MMr>

Ministerio de Economía de México (2016) Crafting the future: a roadmap for industry 4.0 in Mexico. Recuperado de <https://bit.ly/35QY16Y>

Ministerio de Ciencia, Tecnologías, Innovación y Comunicación y Ministerio de Economía de Brasil (2019) Camarada de la Industria 4.0. Plan de Acción de la Cámara Brasilera de la Industria 4.0 de Brasil 2019-2022. Recuperado de <https://url2.cl/Nvvfc>

Pérez, Carlota (2010) “Technological revolutions and techno-economic paradigms". Cambridge Journal of Economics, 34(1) DOI <https://doi.org/10.1093/cje/bep051>

Piketty, Thomas (2014) El Capital en el siglo XXI.Buenos Aires: Fondo de Cultura Económica.

Ramírez Gallegos, René y Sztulwark, Sebastián (2018) América Latina: De la inmovilidad estructural al cambio en la matriz cognitiva. Revista Estado y Políticas Públicas, 6(10); Facultad Latinoamericana de Ciencias Sociales, 21-38.

Rifkin, Jeremy (2014) La sociedad del coste marginal cero: el Internet de las cosas, el procomún colaborativo y el eclipse del capitalismo. Buenos Aires: Editorial Paidós.

Robert, Verónica y Moncaut, Nicolás (2018) "Software y Servicios Informáticos en la ciudad de Tandil. El rol central de la universidad en etapas iniciales de un CAT”. En Graciela Gutman, Silvia Gorenstein, y Verónica Robert. Territorios y nuevas tecnologías: desafíos y oportunidades en Argentina. Buenos Aires: Punto Libro, 141-162. 
Romero Muñoz, José Francisco (2008) Experiencias de vinculación Universidadsector productivo y social en la BUAP. Premio Anuies 2007 a la mejor Tesis de Maestría. Asociación Nacional de Universidades e Instituciones de Educación Superior, México.

Ros Bosch, Jaime (2015) ¿Cómo salir de la trampa del lento crecimiento y alta desigualdad?, México, El Colegio de México y UNAM.

Saavedra García, María Luisa (2009) "Problemática y desafios actuales de la vinculación universidad empresa: El caso mexicano”. Actualidad Contable Faces, 12(19), 100-119.

Sánchez Martín, F., Millán Rodríguez F., Salvador Bayarri J., Palou Redorta J., Rodríguez Escovar F., Esquena Fernández S., Villavicencio Mavrich, H (2007) "Historia de la robótica: de Arquitas de Tarento al robot Da Vinci". Actas Urol Esp. 31(2), 69-76. Recuperado de <https://bit.ly/2QO4qeS>

Schroeder, Wolfgang (2016) La estrategia alemana Industria 4.0: el capitalismo renano en la era de la digitalización. Madrid:Friedrich-Ebert-Stiftung. Recuperado de $<$ https://bit.ly/386RsyD $>$

Schteingart, Daniel, Santarcángelo, Juan y Porta, Fernando (2019) "Cadenas globales de valor, innovación y empresas transnacionales: un abordaje empírico”. Revista Desarrollo Económico, 59(227). 113-150.

Schwab, Klaus (2016) The Fourth Industrial Revolution. New York: Publishing Group.

Secretaría de Economía de México (2018) Política Pública Intersectorial. Innovación e Industria 4.0. Recuperado de <https://prosoft.economia.gob.mx/doc/ PresentacionIndustria.pdf $>$ accesado el 22 de mayo de 2020.

Secretaría de Economía de México (2019) Reglas de Operación del Programa para el Desarrollo de la Industria del Software (PROSOFT) y la Innovación 2019. Recuperado de https://www. gob.mx/se/articulos/conoce-las-reglas-de-operacion-del-programa-para-el-desarrollo-dela-industria-del-software-prosoft-y-la-innovacion-2019 accesado el 22 de mayo de 2020.

Srnicek, Nick (2018) Capitalismo de plataformas. Buenos Aires: Caja Negra.

Sztulwark, Sebastián (2019) "La condición periférica en el nuevo capitalismo". Problemas del Desarrollo, Revista Latinoamericana de Economía, 51(200), DOI < https://doi. org/10.22201/iiec.20078951e.2020.200.68283> 
Zhang, Xianhui, Peek, William, Pikas, Bohdan, Lee, Tenpao (2016) “The Transformation and Upgrading of the Chinese Manufacturing Industry: Based on German Industry 4.0". Journal of Applied Business and Economics, 18(5), 97-105.

Zukerfeld, Mariano (2020) “Bits, plataformas y autómatas. Las tendencias del trabajo en el capitalismo informacional”. Revista Latinoamericana de Antropología del Trabajo, 7, 1-50.

\section{Cómo citar este artículo}

Feldman, Patricio Julián y Ulises Girolimo (2021) "La Industria 4.0 en perspectiva latinoamericana: limitaciones, oportunidades, y desafíos para su desarrollo”. Revista Perspectivas de Políticas Públicas vol. 10 No 20: 459-491 